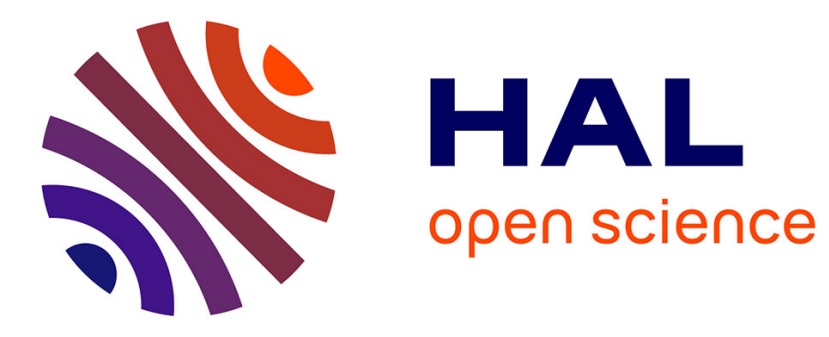

\title{
Neuroimaging features in Posterior Reversible Encephalopathy Syndrome: A Pictorial Review
}

Morgan Ollivier, Anne Bertrand, Frédéric Clarençon, Sophie Gerber, Sandrine Deltour, Fanny Domont, Stéphanie Trunet, Didier Dormont, Delphine Leclercq

\section{To cite this version:}

Morgan Ollivier, Anne Bertrand, Frédéric Clarençon, Sophie Gerber, Sandrine Deltour, et al.. Neuroimaging features in Posterior Reversible Encephalopathy Syndrome: A Pictorial Review. Journal of the Neurological Sciences, 2016, 10.1016/j.jns.2016.12.007 . hal-01427526

\section{HAL Id: hal-01427526 \\ https://hal.inria.fr/hal-01427526}

Submitted on 5 Jan 2017

HAL is a multi-disciplinary open access archive for the deposit and dissemination of scientific research documents, whether they are published or not. The documents may come from teaching and research institutions in France or abroad, or from public or private research centers.
L'archive ouverte pluridisciplinaire HAL, est destinée au dépôt et à la diffusion de documents scientifiques de niveau recherche, publiés ou non, émanant des établissements d'enseignement et de recherche français ou étrangers, des laboratoires publics ou privés. 


\section{Accepted Manuscript}

Neuroimaging features in posterior reversible encephalopathy syndrome: A pictorial review

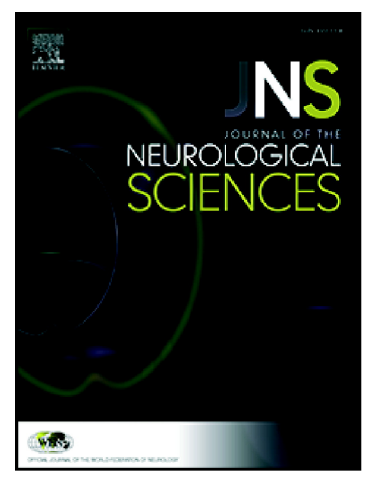

Morgan Ollivier, Anne Bertrand, Frédéric Clarençon, Sophie Gerber, Sandrine Deltour, Fanny Domont, Stéphanie Trunet, Didier Dormont, Delphine Leclercq

PII: $\quad$ S0022-510X(16)30790-0

DOI: $\quad$ doi: $10.1016 / j$ j.jns.2016.12.007

Reference: $\quad$ JNS 14999

To appear in: Journal of the Neurological Sciences

Received date: $\quad 29$ March 2016

Revised date: 6 December 2016

Accepted date: $\quad 7$ December 2016

Please cite this article as: Morgan Ollivier, Anne Bertrand, Frédéric Clarençon, Sophie Gerber, Sandrine Deltour, Fanny Domont, Stéphanie Trunet, Didier Dormont, Delphine Leclercq, Neuroimaging features in posterior reversible encephalopathy syndrome: A pictorial review. The address for the corresponding author was captured as affiliation for all authors. Please check if appropriate. Jns(2016), doi: 10.1016/j.jns.2016.12.007

This is a PDF file of an unedited manuscript that has been accepted for publication. As a service to our customers we are providing this early version of the manuscript. The manuscript will undergo copyediting, typesetting, and review of the resulting proof before it is published in its final form. Please note that during the production process errors may be discovered which could affect the content, and all legal disclaimers that apply to the journal pertain. 


\section{Neuroimaging features in Posterior Reversible Encephalopathy Syndrome: A Pictorial Review}

Morgan Ollivier*

AP-HP, Pitié-Salpétrière Hospital, Department of Functional and Diagnostic Neuroradiology, F-75013

Paris, France

Sorbonne Universités, UPMC Univ Paris 06

Anne Bertrand

AP-HP, Pitié-Salpétrière Hospital, Department of Functional and Diagnostic Neuroradiology, F-75013

Paris

Sorbonne Universités, UPMC Univ Paris 06

Frédéric Clarençon

AP-HP, Pitié-Salpétrière Hospital, Department of Interventional Neuroradiology, F-75013 Paris, France

Sorbonne Universités, UPMC Univ Paris 06

Sophie Gerber

AP-HP, Pitié-Salpétrière Hospital, Department of Functional and Diagnostic Neuroradiology, F-75013

Paris, France

Sandrine Deltour

AP-HP, Pitié-Salpétrière Hospital, Department of Cerebrovascular Diseases, F-75013 Paris, France

Fanny Domont

AP-HP, Pitié-Salpétrière Hospital, Department of Internal Medicine, F-75013 Paris, France

Stéphanie Trunet

AP-HP, Pitié-Salpétrière Hospital, Department of Functional and Diagnostic Neuroradiology, F-75013

Paris, France

Didier Dormont

AP-HP, Pitié-Salpétrière Hospital, Department of Functional and Diagnostic Neuroradiology, F-75013

Paris, France

Sorbonne Universités, UPMC Univ Paris 06

Delphine Leclercq

AP-HP, Pitié-Salpétrière Hospital, Department of Functional and Diagnostic Neuroradiology, F-75013

Paris, France

del.leclercq@gmail.com

Corresponding author at: Service de Neuroradiologie Diagnostique et Fonctionnelle, Hôpital Pitié-

Salpêtrière, 47, Boulevard de l'Hôpital, 75651 Paris Cedex 13, France.

E-mail address: morgan0185@gmail.com

Telephone number: +33674153961 


\section{Neuroimaging features in Posterior Reversible Encephalopathy Syndrome: A Pictorial Review}

\section{KEYWORDS}

Posterior Leukoencephalopathy Syndrome, Magnetic Resonance Imaging, Hemorrhage, Diffusion Magnetic Resonance Imaging, Perfusion Imaging, Arterial Spin-Labeling

\section{ABSTRACT}

Posterior reversible encephalopathy syndrome (PRES) is a radioclinical entity associating nonspecific neurological symptoms (headache, seizures, impairment of alertness, visual disturbances...) occurring in evocative clinical condition (hypertension, eclampsia, immunosuppressor agents, systemic lupus erythematosus...). In the acute stage, the typical imaging finding is a vasogenic edema predominant in the subcortical parietal-occipital white matter.

The purpose of this pictorial review is to illustrate the different neuroimaging features of PRES and present key radiological elements to assert diagnosis. In this overview, we examine the following points: the distributions of vasogenic edema, hemorrhage, the varying patterns in diffusion and perfusion, the different types of enhancement encountered and the vascular modifications demonstrated by angiography. The cause of PRES is still unknown. Nevertheless, catheter angiography, MR angiography and MR perfusion features in PRES render further insight into its pathophysiology.

Follow-up imaging shows evidence of radiologic improvement in the very large majority of cases in 1 or 2 weeks, sometimes in up to 1 month. Recurrent PRES attacks are uncommon.

Atypical imaging presentation should not reject the diagnosis of PRES in a compatible clinical situation.

\section{INTRODUCTION}

PRES is a clinicoradiologic entity occurring in evocative clinical condition. Most cases of PRES occur in association with hypertension and/or immunosuppression. The 
main cause of PRES is acute elevation of blood pressure above the upper limit of cerebral blood flow autoregulation. ${ }^{1}$ Besides hypertensive encephalopathy, PRES has been recognized in an increasing number of medical conditions, including preeclampsia and eclampsia ${ }^{2-5}$, vasculitis (Wegener's granulomatosis, systemic lupus erythematosus $)^{6}$, acute or chronic renal diseases ${ }^{7,8}$, use of immunosuppressive drugs (Ciclosporine A, Tacrolimus, Vincristine, Cisplatin....) ${ }^{9-12}$, sepsis and shock $^{13}$, blood transfusion ${ }^{14} \ldots$

Clinical signs and symptoms include headache, seizures, usually with electroencephalographic abnormalities most prominent over the posterior cortex, visual disturbances, including blurred vision, flashing lights or cortical blindness and hemiparesis. ${ }^{15,16}$

PRES may be suspected on the basis of history but the clinical findings are nonspecific so the diagnosis may be difficult to establish. Recognition of the characteristic imaging findings by radiologists is the key to diagnose this syndrome. MRI is the imaging mode of choice for the diagnosis and the follow-up in PRES.

Two theories have been promoted to explain the pathophysiology of vasogenic edema in PRES. In patients with hypertensive encephalopathy and in pregnant patients with eclampsia, PRES is thought to occur after a subacute elevation in blood pressure. Hypertension, when severe, may exceed the limit of autoregulation, leading to hyperperfusion and breakthrough vasogenic edema. ${ }^{17}$ Nevertheless, PRES developing and spontaneously reversing in normotensive patients suggests another mechanism than hypertension. ${ }^{13}$ Thus, the second hypothesized mechanism involves endothelial dysfunction secondary to systemic toxicity ${ }^{16}$ in immuno-suppressive therapy, eclampsia and sepsis. Intense cytokine response involving interleukin (IL-1, IL6) and tumour necrosis factor (TNF-a) in eclampsia ${ }^{18}$ and sepsis $^{19}$ as well as immunosuppressors ${ }^{20}$ are known to cause endothelial cell injury

\section{DISTRIBUTION}

The abnormalities affect primarily the subcortical white matter and often extend to the cortical surface sparing the deep white matter. Cortical, subcortical white matter and deep white matter edema are present in 18 to $29.0 \%$ of cases ${ }^{21,22}$ (Fig. 1-3).

Focal or confluent vasogenic edema is present in the classic posterior parietal or occipital lobe region most consistently $(\geq 98 \%)^{21,22}$ with additional involvement of the frontal lobes $(\approx 70 \%)$, temporal region $(\approx 65 \%)$ and cerebellum (30 to $53 \%)^{21-23}$ (Fig. 4). The distribution of lesions is mainly symmetrical $(71 \%)^{24}$, but can be asymmetric (Fig. 5) and even completely unilateral, simulating neoplasm. ${ }^{24}$ Bartynski WS. et al. describe three primary variations of the traditional PRES imaging pattern ${ }^{21}$ : - Superior Frontal Sulcus Pattern with frontal abnormality linear and located along the superior frontal sulcus and no frontal pole extension, associated with varying degrees of parietal and occipital abnormality (Fig. 6A).

- Holohemispheric Watershed Pattern spanning the frontal, parietal and occipital lobes with vasogenic edema present at the watershed (Fig. 6B).

- Dominant Parietal-Occipital Pattern with involvement of the parietal and occipital white matter and cortex with variable involvement of the temporal lobes (Fig. 6C). 
The preferential distribution of white matter lesions in posterior brain regions is not well understood. Topographic variation in the cerebrovascular sympathetic innervation may be important ${ }^{25}$ and is generally accepted to result from the relatively sparse sympathetic innervation of the vertebrobasilar circulation ${ }^{26}$. The density of sympathetic innervation is maximal in the internal carotid and anterior cerebral territories. ${ }^{25,26}$ Sympathetic mediated vasoconstriction may be more effective in protecting the perforating small arterioles in the anterior circulation from overperfusion in acute hypertension. ${ }^{27}$ Because of this anterior to posterior gradient of sympathetic innervation, hyperperfusion state in perforating white matter arterioles and resulting edema might occur with a posterior to anterior gradient in patients with PRES. ${ }^{28}$

Less common areas of additional involvement include the thalamus $(\approx 30 \%)$, basal ganglia (11,8 to $34 \%)$ and brainstem (12,5 to 27\% $)^{21-23}$ (Fig. 7). Isolated and extensive involvement of one or more of these structures without involvement of the parieto-occipital region is uncommon.

Isolated involvement of the posterior fossa structures is rare. Posterior fossa lesions can lead to hydrocephalus and tonsillar herniation in the most severe cases. Some articles report brainstem and/or cerebellum extensively involved with supratentorial structures completely spared. ${ }^{29-31}$ This variant of PRES with predominant involvement of the posterior fossa remains unexplained. It has been reported that mild hypertension induces edema predominantly in the supratentorial white matter, whereas severe hypertension induces vasogenic edema in infratentorial structures, basal ganglia and thalamus ${ }^{32}$. Indeed animal studies have shown that mild acceleration of hypertension produced edema predominantly in the supratentorial white matter, while severe blood pressure elevations produced vasogenic edema infratentorially, as well as in the basal ganglia and thalamus. A greater involvement of the brainstem and deep structures at higher blood pressure maybe related to presence of small arteries that originate directly from larger trunks such as the middle cerebral artery and the basilar artery or its branches and thus subjected to high perfusion pressure levels. A severe elevation of blood pressure may be required for a blood-brain barrier breakdown in this location. ${ }^{32}$ Several articles studied whether the distribution of the lesions differed in hypertensive or normotensive PRES, with contradictory results. ${ }^{16,23}$

In Li et al. study including 28 patients, no significant difference existed in terms of the MRI distribution of vasogenic edema between PRES due to primary hypertension and PRES due to secondary causes. ${ }^{16}$ On the other hand, Fugate et al. demonstrated in a large clinical series (113 patients) that cerebellar involvement was significantly more frequent in patients with a history of autoimmunity compared with those without autoimmunity. $^{23}$

Nine cases of spinal cord involvement are reported in the literature ${ }^{33-39}$. All patients had confluent expansile central spinal cord T2 hyperintensity spanning at least 4 spinal segments, originating at the cervicomedullary junction. Only 5 of 9 patients had supratentorial involvement but all patients had brainstem involvement. All patients had severe acute hypertension. In one third of the cases clinical symptoms of spinal cord involvement were absent. De Havenon et al. propose a new syndrome named PRES with spinal cord involvement (PRES-SCI) that should be suspected when patients with PRES have neurologic signs referable to the spinal cord, extreme elevation in blood pressure, MRI lesions that extend to the cervicomedullary junction, or grade IV hypertensive retinopathy. ${ }^{39}$ 


\section{HEMORRHAGE}

Intracranial hemorrhage is known to occur in PRES in approximately 15$64 \%{ }^{22,40,41}$ Three distinct types of hemorrhage could be identified: minute foci of hemorrhage $(<5 \mathrm{~mm})$ are more common than subarachnoid hemorrhage in cortical sulci or intraparenchymal hematomas ${ }^{41}$. Single or combined hemorrhage types could be present (Fig.1). Susceptibility-Weighted Imaging is more sensitive than conventional T2* gradient-recalled echo imaging in detecting cerebral hemorrhage and especially microhemorrhage. ${ }^{41}$

The mechanism of hemorrhage is presumed to arise from the phenomenon of breakthrough perfusion: rupture of pial vessels in the face of severe hypertension or vasoconstriction coupled with blood pressure instability predisposing to reperfusion injury ${ }^{42}$.

Hemorrhage type and frequency do not appear to be linked to blood pressure in patients with PRES. On the other hand, the rate of hemorrhage is greater in patients undergoing therapeutic anticoagulation and after allogeneic bone marrow transplantation compared with those with solid-organ transplantation. ${ }^{40}$ The incidence of microhemorrhage does not seem to correlate with the severity or extent of edema, the presence of DWI-positive findings or the presence of enhancement. Most microhemorrhage appear to persist on long-term follow-up. ${ }^{41}$

\section{DIFFUSION}

Apparent diffusion coefficient (ADC) values in areas of abnormal T2 signal intensity are typically elevated consistent with highly mobile water in areas of vasogenic edema in PRES. These areas with increased ADC values may appear hyperintense, hypointense, or isointense on diffusion-weighted imaging (DWI), depending on the amount of the T2 "shine-through" effect. ${ }^{43-45}$ The majority of lesions appear hypointense or isointense on diffusion-weighted imaging (DWI). ${ }^{44}$ This phenomenon is called T2 washout ${ }^{45}$ : isointense lesions on DWI result from a perfect balance of T2 effects and increased water diffusibility whereas hypointense lesions on DWI have higher ADC values, which are not balanced by T2 effects (Fig. 11).

In some cases, ADC values can be paradoxically normal in areas of high DWI signal. ${ }^{44}$ These so called pseudonormalized ADC values may result from intravoxel averaging of both cytotoxic and vasogenic edema in the cortex affected by PRES. High DWI signal intensity and pseudonormalized ADC values seem to be correlated with cerebral infarction and may represent the earliest sign of nonreversibility as severe vasogenic edema progresses to cytotoxic edema ${ }^{44}$.

Focal areas of restricted diffusion are uncommon (11-26\%). ${ }^{21,23}$ Coexistence of hypointense and hyperintense lesions on ADC mapping of the affected areas is frequently observed but purely cytotoxic edema is also reported. ${ }^{24,46}$ Many studies have shown that increased ADC values indicate vasogenic edema, most often reversible, while decreased ADC values indicate cytotoxic edema that inevitably induces cell death and progression to true infarction ${ }^{4,15,28,44,47}$. However, more recent studies produced contradictory results. In Kastrup et al. study of 50 patients with PRES, 
two patients with purely cytotoxic edema did not show conversion to infarction. ${ }^{24}$ Several case reports illustrate reversibility of diffusion anomalies with restricted ADC in patients with PRES. ${ }^{46,48,49}$ Thus restricted diffusion does not always indicated irreversible lesions (Fig. 2).

Seizures are a frequent manifestation of PRES and occipital lobe seizures are usually described as a common manifestation of this syndrome. ${ }^{50}$ Status epilepticus is reported in about $15 \%$ of patients with PRES $^{51}$. It is often the main manifestation of PRES after pediatric allogeneic hematopoietic stem cell transplantation and could be a life-threatening event ${ }^{52}$. Status epilepticus in itself can lead to MRI changes ${ }^{53}$ : hyperintensity on diffusion-weighted imaging with restricted diffusion involving the cortex and/or the ipsilateral pulvinar nuclei of the thalamus. Wakisaka et al. ${ }^{54}$ reported peri-ictal $\mathrm{MRI}$ findings in a patient with PRES that developed generalized tonic-clonic seizures. They demonstrated a gyriform cortical hyperintensity on DWI with decreased ADC around the sub-cortical occipitoparietal main PRES lesion with hyperintensity on DWI and increased ADC. These findings suggest that acute symptomatic partial epilepsy develops around the epileptogenic PRES lesion.

\section{PERFUSION}

The cerebral vasculature is capable of maintaining a relatively constant flow of blood to the brain tissues over large fluctuations of systemic blood pressures. Two competing hypotheses have been suggested for the mechanism of brain edema formation in PRES.

The hyperperfusion theory remains widely accepted: severe hypertension with autoregulatory failure induces excessive blood flow and elevated capillary hydrostatic pressure, which causes fluid to leave the vessels and pass into the interstitial spaces. Investigating the brain effects of severe hypertension, a series of animal studies demonstrate that when the upper limits of autoregulation are exceeded, breakthrough occurs with the development of blood vessel alteration, capillary bed injury, vasogenic edema, and hyperperfusion. ${ }^{55,56}$ Case reports of patients studied with technetium Tc99m-hexamethylpropyleneamine oxime (Tc99m-HMPAO) single-photon emission CT (SPECT) or with Arterial Spin Labeling $(A S L)^{57}$ showed increased perfusion in the vicinity of the brain that had abnormal signal.

The alternate hypothesis is that the hypertension induces compensator vasoconstriction, leading to decreased perfusion, brain ischemia and subsequent edema (Fig. 5, 12). Perfusion MR imaging is able to measure the cerebral blood volume (CBV), cerebral blood flow (CBF), mean transit time (MTT) and vascular permeability (K2). Bartynski W.S. et al. study found a rCBV markedly diminished ( $\leq 80 \%$ average) in $86 \%$ of PRES lesions and regions compared with the healthy reference cortex. Brubaker L.M. et al. highlighted decreased posterior rCBF and rCBV, with heterogeneous patterns of MTT without changes in permeability by using the measure $\mathrm{K} 2$ and suggested that the interstitial edema seen in PRES might be caused by the elevation of capillary hydrostatic pressure mediated by venous constriction. ${ }^{58}$

Hypoperfusion and hyperperfusion phenomenon could be intricately linked. Changes with time in the same patient with PRES are described, including initial vasoconstriction and hypoperfusion followed by rebound hyperperfusion. ${ }^{59}$ 
rCBF color map can demonstrate increased perfusion in the occipital regions in a patient with PRES (Fig. 8, 9, 10). These perfusion abnormalities can be more extensive than FLAIR hyperintensities and are reversible (Fig. 8). In figure 9, increased perfusion preceded FLAIR hyperintensities in a symptomatic patient with recurrent PRES; to our knowledge, no other study has reported a comparable case. Hemodynamic changes can also be observed in peri-ictal states with focal cortical DWI hyperintensity and strong cortical hyperperfusion on ASL. In interictal state, hyperintense signals on DWI disappears and ASL demonstrates hypoperfusion or normal perfusion. ${ }^{60,61}$ In our case (Fig. 9), cortical hyperperfusion was symmetrical, contemporary with severe headache, preceded the seizure and can therefore be attributed to PRES.

\section{ENHANCEMENT}

Intravenous contrast administration is not indicated to diagnose PRES but may be useful to exclude other clinical considerations.

No enhancement or a slight cortical enhancement is typically observed. Contrast enhancement is reported in a variable incidence, ranking from 23 to $43 \%$. $22,24,62$ Leptomeningeal enhancement superficially above the brain surface is the most common pattern $^{62}$ (Fig.13). Occasionally, a marked gyriform cortical enhancement can be observed. ${ }^{43}$

Leptomeningeal and cortical enhancement occur secondary to the breakdown of the blood-brain barrier. ${ }^{63}$ The pathophysiologic mechanisms of enhancement in PRES is related to endothelial injury or dysfunction. The direct toxic effects of tacrolimus and ciclosporin on cerebral endothelial cells have been demonstrated in animal models, these drugs induce apoptosis on the brain capillary endothelial cells. ${ }^{20}$ As a rule, enhancement in PRES corresponds to the sites of parenchymal involvement. However, leptomeningeal enhancement occurring distant from the site of parenchymal involvement is possible. ${ }^{64}$

Compared to contrast-enhanced T1 weighted imaging, contrast enhanced fluid attenuated inversion recovery (CE-FLAIR) has been reported to have superior specificity and similar sensitivity in the detection of the inflammatory leptomeningeal lesions ${ }^{65}$. It also seems to be true in PRES leptomeningeal lesions (Fig. 7). Increased fluidattenuated inversion recovery signal intensity in the subarachnoid spaces on delayed enhanced MR imaging is also possible, believed due to cerebrospinal fluid gadolinium enhancement. ${ }^{66}$

\section{VASOSPASM}

Vasculopathy is a common finding on catheter angiography or MR angiography in patients with PRES regardless of the cause. A multifocal cerebral vasoconstriction is noted in more than $85 \%$ of patients with PRES.,13,67 Catheter angiography can demonstrate focal vasoconstriction, focal vasodilatation, string-of-bead appearance (Fig. 13) most commonly observed in the second- and third-order branches and frequently associated with regions of vasogenic edema. ${ }^{13,68}$ Follow-up imaging demonstrates 
reversal of vessel irregularities. ${ }^{5,13}$

These imaging features are close to those of the Reversible Cerebral Vasoconstriction Syndromes (RCVS). PRES and RCVS share many clinicoradiographic features, suggesting overlapping or similar pathophysiological mechanisms. ${ }^{69}$ Also, reversible brain edema occurs in $9-38 \%$ of all cases of RCVS. ${ }^{70,71}$

\section{FOLLOW-UP}

Follow-up imaging shows evidence of radiologic improvement in the very large majority of cases with complete or near-complete resolution of abnormalities in about $70 \%$ of cases $^{23,24}$. Some patients reach complete resolution in 1 or 2 weeks and others experience widespread regression in up to 1 month (Fig. 5). ${ }^{24}$

The syndrome is reversible if adequately treated ${ }^{72,73}$. High blood pressure treatment is important to avoid pronounced fluctuations of blood pressure. In patients with drug related and eclampsia related PRES, cessation of the immunosuppressant and delivery allows resolution of PRES.

Recurrent PRES attacks are rare (3,8-14\%). ${ }^{74,75,16} \mathrm{Li} R$. et al. ${ }^{17}$ have demonstrated that patients with systemic hypertension as the primary etiology had a significantly higher rate of recurrence than patients with other causes of PRES (immunosuppression, chemotherapy, eclampsia....). They speculate that poor drug compliance in these patients has led to poor blood pressure control, predisposing them to higher risk of recurrence. ${ }^{16}$

Despite its name and classic reversibility, many patients still have permanent neurologic sequelae with a fatal out-come related to PRES in approximately $5-19 \%{ }^{76,77}$. Risk factors for fatal outcome in PRES are not well identified. It seems that the influential factor to prognosis is the reversibility of lesions and hemorrhage. ${ }^{78,79}$ Hemorrhage on imaging portended the highest risk of fatal outcome. Not only frank intraparenchymal hematomas but also microhemorrhage appear to be correlated with a worse patient prognosis. $^{77}$

\section{CONCLUSION}

Vasogenic edema is most consistently present in the classic posterior parietal or occipital lobes. But despite the syndrome's name, radiographic lesions in PRES are rarely isolated to the "posterior" parieto-occipital white matter and often involve the cortex, frontal lobes, temporal regions, cerebellum, thalamus and brainstem. $\mathrm{MRI}$ is an efficient tool for early diagnosis and follow-up in PRES but atypical imaging findings must be known in order not to mistakenly reject the diagnosis of PRES: -hemorrhage is a common complication

-DWI is essential but decrease in ADC values does not always correlate with nonreversibility of the lesions

-intravenous contrast administration may demonstrate focal enhancement

-perfusion MR imaging can demonstrate increased or decreased perfusion. Increased perfusion can precede the brain abnormalities on FLAIR images. 
-multifocal cerebral vasoconstriction is commonly observed.

\section{REFERENCES}

1. Hinchey $\mathrm{J}$, Chaves $\mathrm{C}$, Appignani B, et al. A reversible posterior leukoencephalopathy syndrome. N Engl J Med. 1996;334(8):494-500. doi:10.1056/NEJM199602223340803.

2. Apollon KM, Robinson JN, Schwartz RB, Norwitz ER. Cortical blindness in severe preeclampsia: computed tomography, magnetic resonance imaging, and single-photonemission computed tomography findings. Obstet Gynecol. 2000;95(6 Pt 2):1017-1019. 3. Junewar V, Verma R, Sankhwar PL, et al. Neuroimaging features and predictors of outcome in eclamptic encephalopathy: a prospective observational study. AJNR Am J Neuroradiol. 2014;35(9):1728-1734. doi:10.3174/ajnr.A3923.

4. Koch S, Rabinstein A, Falcone S, Forteza A. Diffusion-weighted imaging shows cytotoxic and vasogenic edema in eclampsia. AJNR Am J Neuroradiol. 2001;22(6):10681070.

5. Sengar AR, Gupta RK, Dhanuka AK, Roy R, Das K. MR imaging, MR angiography, and MR spectroscopy of the brain in eclampsia. AJNR Am J Neuroradiol. 1997;18(8):1485-1490.

6. Primavera A, Audenino D, Mavilio N, Cocito L. Reversible posterior leucoencephalopathy syndrome in systemic lupus and vasculitis. Ann Rheum Dis. 2001;60(5):534-537.

7. Sfaihi L, Kamoun F, Hentati Y, et al. [Posterior reversible encephalopathy syndrome induced by acute postinfectious glomerulonephritis]. Arch Pédiatrie Organe Off Sociéte Fr Pédiatrie. 2013;20(6):633-636. doi:10.1016/j.arcped.2013.03.014.

8. Canney M, Kelly D, Clarkson M. Posterior reversible encephalopathy syndrome in end-stage kidney disease: not strictly posterior or reversible. Am J Nephrol. 2015;41(3):177-182. doi:10.1159/000381316.

9. Oda N, Kato TS, Hanatani A, et al. Reversible posterior leukoencephalopathy syndrome (RPLS) in a heart transplant recipient treated by substitution of cyclosporine A with tacrolimus. Intern Med Tokyo Jpn. 2010;49(11):1013-1016.

10. Loar RW, Patterson MC, O'Leary PW, Driscoll DJ, Johnson JN. Posterior reversible encephalopathy syndrome and hemorrhage associated with tacrolimus in a pediatric heart transplantation recipient. Pediatr Transplant. 2013;17(2):E67-E70. doi:10.1111/petr.12039.

11. Hurwitz RL, Mahoney DH, Armstrong DL, Browder TM. Reversible encephalopathy and seizures as a result of conventional vincristine administration. Med Pediatr Oncol. 1988;16(3):216-219.

12. Ito $\mathrm{Y}$, Arahata $\mathrm{Y}$, Goto $\mathrm{Y}$, et al. Cisplatin neurotoxicity presenting as reversible posterior leukoencephalopathy syndrome. AJNR Am J Neuroradiol. 1998;19(3):415-417. 13. Bartynski WS, Boardman JF. Catheter angiography, MR angiography, and MR perfusion in posterior reversible encephalopathy syndrome. AJNR Am J Neuroradiol. 2008;29(3):447-455. doi:10.3174/ajnr.A0839.

14. Heo K, Park SA, Lee JY, Lee BI, Lee S-K. Post-transfusion posterior leukoencephalopathy with cytotoxic and vasogenic edema precipitated by vasospasm. 
Cerebrovasc Dis Basel Switz. 2003;15(3):230-233. doi:68825.

15. Schwartz RB, Jones KM, Kalina P, et al. Hypertensive encephalopathy: findings on CT, MR imaging, and SPECT imaging in 14 cases. AJR Am J Roentgenol. 1992;159(2):379-383. doi:10.2214/ajr.159.2.1632361.

16. Li R, Mitchell P, Dowling R, Yan B. Is hypertension predictive of clinical recurrence in posterior reversible encephalopathy syndrome? J Clin Neurosci Off J Neurosurg Soc Australas. 2013;20(2):248-252. doi:10.1016/j.jocn.2012.02.023.

17. Strandgaard S, Olesen J, Skinhoj E, Lassen NA. Autoregulation of brain circulation in severe arterial hypertension. Br Med J. 1973;1(5852):507-510.

18. Benyo DF, Smarason A, Redman CW, Sims C, Conrad KP. Expression of inflammatory cytokines in placentas from women with preeclampsia. $J$ Clin Endocrinol Metab. 2001;86(6):2505-2512. doi:10.1210/jcem.86.6.7585.

19. Aird WC. The role of the endothelium in severe sepsis and multiple organ dysfunction syndrome. Blood. 2003;101(10):3765-3777. doi:10.1182/blood-2002-061887.

20. Kochi $\mathrm{S}$, Takanaga $\mathrm{H}$, Matsuo $\mathrm{H}$, et al. Induction of apoptosis in mouse brain capillary endothelial cells by cyclosporin A and tacrolimus. Life Sci. 2000;66(23):22552260.

21. Bartynski WS, Boardman JF. Distinct imaging patterns and lesion distribution in posterior reversible encephalopathy syndrome. AJNR Am J Neuroradiol. 2007;28(7):1320-1327. doi:10.3174/ajnr.A0549.

22. McKinney AM, Short J, Truwit CL, et al. Posterior reversible encephalopathy syndrome: incidence of atypical regions of involvement and imaging findings. AJR Am J Roentgenol. 2007;189(4):904-912. doi:10.2214/AJR.07.2024.

23. Fugate JE, Claassen DO, Cloft HJ, Kallmes DF, Kozak OS, Rabinstein AA. Posterior Reversible Encephalopathy Syndrome: Associated Clinical and Radiologic Findings. Mayo Clin Proc. 2010;85(5):427-432. doi:10.4065/mcp.2009.0590.

24. Kastrup O, Schlamann M, Moenninghoff C, Forsting M, Goericke S. Posterior Reversible Encephalopathy Syndrome: The Spectrum of MR Imaging Patterns. Clin Neuroradiol. February 2014. doi:10.1007/s00062-014-0293-7.

25. Sundt TM. The cerebral autonomic nervous system. A proposed physiologic function and pathophysiologic response in subarachnoid hemorrhage and in focal cerebral ischemia. Mayo Clin Proc. 1973;48(2):127-137.

26. Edvinsson L, Owman C, Sjöberg NO. Autonomic nerves, mast cells, and amine receptors in human brain vessels. A histochemical and pharmacological study. Brain Res. 1976;115(3):377-393.

27. Heistad DD. Protection of the blood-brain barrier during acute and chronic hypertension. Fed Proc. 1984;43(2):205-209.

28. Ay H, Buonanno FS, Schaefer PW, et al. Posterior leukoencephalopathy without severe hypertension: utility of diffusion-weighted MRI. Neurology. 1998;51(5):13691376.

29. Karakis I, Macdonald JA, Stefanidou M, Kase CS. Clinical and radiological features of brainstem variant of hypertensive encephalopathy. J Vasc Interv Neurol. 2009;2(2):172-176.

30. Shimizu $\mathrm{Y}$, Tha KK, Iguchi A, et al. Isolated Posterior Fossa Involvement in Posterior Reversible Encephalopathy Syndrome. Neuroradiol J. 2013; 26(5):514-519. 31. Li D, Lian L, Zhu S. Isolated cerebellar involvement in posterior reversible 
encephalopathy syndrome. J Neurol Sci. 2015;357(1-2):101-105.

doi:10.1016/j.jns.2015.07.004.

32. Kumai Y, Toyoda K, Fujii K, Ibayashi S. Hypertensive encephalopathy extending into the whole brainstem and deep structures. Hypertens Res Off J Jpn Soc Hypertens. 2002;25(5):797-800.

33. Milia A, Moller J, Pilia G, et al. Spinal cord involvement during hypertensive encephalopathy: clinical and radiological findings. J Neurol. 2008;255(1):142-143. doi:10.1007/s00415-008-0698-9.

34. Nagato M, Takahashi Y, Yoshioka M, Nambu M. A case of hypertensive encephalopathy with extensive spinal lesions on MRI. Brain Dev. 2010;32(7):598-601. doi:10.1016/j.braindev.2009.07.002.

35. Choh NA, Jehangir M, Rasheed M, Mira T, Ahmad I, Choh S. Involvement of the cervical cord and medulla in posterior reversible encephalopathy syndrome. Ann Saudi Med. 2011;31(1):90-92. doi:10.4103/0256-4947.75790.

36. Hou X, Xu J, Chen Z, Li G, Jiang H. Posterior Reversible Encephalopathy Syndrome with Involvement of the Cervical Cord and Medulla: A Case Report. J Clin Diagn Res JCDR. 2015;9(1):CD01-CD02. doi:10.7860/JCDR/2015/10756.5376.

37. Briganti C, Caulo M, Notturno F, Tartaro A, Uncini A. Asymptomatic spinal cord involvement in posterior reversible encephalopathy syndrome. Neurology. 2009;73(18):1507-1508. doi:10.1212/WNL.0b013e3181bf98c9.

38. Hagan IG, Burney K. Radiology of recreational drug abuse. Radiogr Rev Publ Radiol Soc N Am Inc. 2007;27(4):919-940. doi:10.1148/rg.274065103.

39. De Havenon A, Joos Z, Longenecker L, Shah L, Ansari S, Digre K. Posterior reversible encephalopathy syndrome with spinal cord involvement. Neurology. 2014;83(22):2002-2006. doi:10.1212/WNL.0000000000001026.

40. Hefzy HM, Bartynski WS, Boardman JF, Lacomis D. Hemorrhage in posterior reversible encephalopathy syndrome: imaging and clinical features. AJNR Am J Neuroradiol. 2009;30(7):1371-1379. doi:10.3174/ajnr.A1588.

41. McKinney AM, Sarikaya B, Gustafson C, Truwit CL. Detection of microhemorrhage in posterior reversible encephalopathy syndrome using susceptibilityweighted imaging. AJNR Am J Neuroradiol. 2012;33(5):896-903. doi:10.3174/ajnr.A2886.

42. Doss-Esper CE, Singhal AB, Smith MSA, Henderson GV. Reversible posterior leukoencephalopathy, cerebral vasoconstriction, and strokes after intravenous immune globulin therapy in guillain-barre syndrome. J Neuroimaging Off J Am Soc Neuroimaging. 2005;15(2):188-192. doi:10.1177/1051228404273820.

43. Lamy C, Oppenheim C, Méder JF, Mas JL. Neuroimaging in posterior reversible encephalopathy syndrome. J Neuroimaging Off J Am Soc Neuroimaging. 2004;14(2):8996.

44. Covarrubias DJ, Luetmer PH, Campeau NG. Posterior Reversible Encephalopathy Syndrome: Prognostic Utility of Quantitative Diffusion-Weighted MR Images. Am J Neuroradiol. 2002;23(6):1038-1048.

45. Provenzale JM, Petrella JR, Cruz LC, Wong JC, Engelter S, Barboriak DP. Quantitative assessment of diffusion abnormalities in posterior reversible encephalopathy syndrome. AJNR Am J Neuroradiol. 2001;22(8):1455-1461.

46. Yilmaz S, Gokben S, Arikan C, Calli C, Serdaroglu G. Reversibility of Cytotoxic Edema in Tacrolimus Leukoencephalopathy. Pediatr Neurol. 2010;43(5):359-362. 
doi:10.1016/j.pediatrneurol.2010.05.021.

47. Schaefer PW, Buonanno FS, Gonzalez RG, Schwamm LH. Diffusion-weighted imaging discriminates between cytotoxic and vasogenic edema in a patient with eclampsia. Stroke J Cereb Circ. 1997;28(5):1082-1085.

48. Benziada-Boudour A, Schmitt E, Kremer S, et al. Posterior reversible encephalopathy syndrome: a case of unusual diffusion-weighted MR images. $J$ Neuroradiol J Neuroradiol. 2009;36(2):102-105. doi:10.1016/j.neurad.2008.08.003.

49. Gupta R. Restricted diffusion in chemotherapy-induced posterior reversible encephalopathy syndrome: Not necessarily a bad omen? Indian J Cancer. 2014;51(3):372-373. doi:10.4103/0019-509X.146716.

50. Bakshi R, Bates VE, Mechtler LL, Kinkel PR, Kinkel WR. Occipital Lobe Seizures as the Major Clinical Manifestation of Reversible Posterior Leukoencephalopathy Syndrome: Magnetic Resonance Imaging Findings. Epilepsia. 1998;39(3):295-299. doi:10.1111/j.1528-1157.1998.tb01376.x.

51. Kozak OS, Wijdicks EFM, Manno EM, Miley JT, Rabinstein AA. Status epilepticus as initial manifestation of posterior reversible encephalopathy syndrome. Neurology. 2007;69(9):894-897. doi:10.1212/01.wnl.0000269780.45472.16.

52. Cordelli DM, Masetti R, Bernardi B, et al. Status epilepticus as a main manifestation of posterior reversible encephalopathy syndrome after pediatric hematopoietic stem cell transplantation. Pediatr Blood Cancer. 2012;58(5):785-790. doi:10.1002/pbc.23344.

53. Szabo K, Poepel A, Pohlmann-Eden B, et al. Diffusion-weighted and perfusion MRI demonstrates parenchymal changes in complex partial status epilepticus. Brain J Neurol. 2005;128(Pt 6):1369-1376. doi:10.1093/brain/awh454.

54. Wakisaka K, Morioka T, Shimogawa T, et al. Epileptic Ictal Hyperperfusion on Arterial Spin Labeling Perfusion and Diffusion-Weighted Magnetic Resonance Images in Posterior Reversible Encephalopathy Syndrome. J Stroke Cerebrovasc Dis. 2016;25(1):228-237. doi:10.1016/j.jstrokecerebrovasdis.2015.09.023.

55. Kontos HA, Wei EP, Navari RM, Levasseur JE, Rosenblum WI, Patterson JL. Responses of cerebral arteries and arterioles to acute hypotension and hypertension. Am J Physiol. 1978;234(4):H371-H383.

56. MacKenzie ET, Strandgaard S, Graham DI, Jones JV, Harper AM, Farrar JK. Effects of acutely induced hypertension in cats on pial arteriolar caliber, local cerebral blood flow, and the blood-brain barrier. Circ Res. 1976;39(1):33-41.

57. Ollivier M, Wanono E, Leclercq D, et al. Transient reduction in venous susceptibility during posterior reversible encephalopathy syndrome. J Neurol Sci. September 2015. doi:10.1016/j.jns.2015.09.359.

58. Brubaker LM, Smith JK, Lee YZ, Lin W, Castillo M. Hemodynamic and permeability changes in posterior reversible encephalopathy syndrome measured by dynamic susceptibility perfusion-weighted MR imaging. AJNR Am J Neuroradiol. 2005;26(4):825-830.

59. Deibler AR, Pollock JM, Kraft RA, Tan H, Burdette JH, Maldjian JA. Arterial spinlabeling in routine clinical practice, part 3: hyperperfusion patterns. AJNR Am J Neuroradiol. 2008;29(8):1428-1435. doi:10.3174/ajnr.A1034.

60. Oishi M, Ishida G, Morii K, Hasegawa K, Sato M, Fujii Y. Ictal focal hyperperfusion demonstrated by arterial spin-labeling perfusion MRI in partial epilepsy status. Neuroradiology. 2012;54(6):653-656. doi:10.1007/s00234-012-1027-7. 
61. Matsuura K, Maeda M, Okamoto K, et al. Usefulness of arterial spin-labeling images in periictal state diagnosis of epilepsy. J Neurol Sci. 2015;359(1-2):424-429. doi:10.1016/j.jns.2015.10.009.

62. Karia SJ, Rykken JB, McKinney ZJ, Zhang L, McKinney AM. Utility and Significance of Gadolinium-Based Contrast Enhancement in Posterior Reversible Encephalopathy Syndrome. AJNR Am J Neuroradiol. 2016;37(3):415-422. doi:10.3174/ajnr.A4563.

63. Smirniotopoulos JG, Murphy FM, Rushing EJ, Rees JH, Schroeder JW. Patterns of contrast enhancement in the brain and meninges. Radiogr Rev Publ Radiol Soc N Am Inc. 2007;27(2):525-551. doi:10.1148/rg.272065155.

64. Fitzgerald RT, Osorio J, Panigrahy A, Mazariegos GV, Zuccoli G. Isolated leptomeningeal enhancement in tacrolimus-associated posterior reversible encephalopathy syndrome. Pediatr Neurol. 2013;48(1):76-78. doi:10.1016/j.pediatrneurol.2012.09.002.

65. Kremer S, Abu Eid M, Bierry G, et al. Accuracy of delayed post-contrast FLAIR MR imaging for the diagnosis of leptomeningeal infectious or tumoral diseases. $J$ Neuroradiol J Neuroradiol. 2006;33(5):285-291.

66. Hamilton BE, Nesbit GM. Delayed CSF enhancement in posterior reversible encephalopathy syndrome. AJNR Am J Neuroradiol. 2008;29(3):456-457. doi:10.3174/ajnr.A0926.

67. Bartynski WS, Boardman JF, Zeigler ZR, Shadduck RK, Lister J. Posterior reversible encephalopathy syndrome in infection, sepsis, and shock. AJNR Am J Neuroradiol. 2006;27(10):2179-2190.

68. Stevens CJ, Heran MKS. The many faces of posterior reversible encephalopathy syndrome. Br J Radiol. 2012;85(1020):1566-1575. doi:10.1259/bjr/25273221.

69. Ducros A. Reversible cerebral vasoconstriction syndrome. Handb Clin Neurol. 2014;121:1725-1741. doi:10.1016/B978-0-7020-4088-7.00111-5.

70. Ducros A, Boukobza M, Porcher R, Sarov M, Valade D, Bousser M-G. The clinical and radiological spectrum of reversible cerebral vasoconstriction syndrome. A prospective series of 67 patients. Brain J Neurol. 2007;130(Pt 12):3091-3101. doi:10.1093/brain/awm256.

71. Singhal AB, Hajj-Ali RA, Topcuoglu MA, et al. Reversible cerebral vasoconstriction syndromes: analysis of 139 cases. Arch Neurol. 2011;68(8):1005-1012. doi:10.1001/archneurol.2011.68.

72. Fugate JE, Rabinstein AA. Posterior reversible encephalopathy syndrome: clinical and radiological manifestations, pathophysiology, and outstanding questions. Lancet Neurol. 2015;14(9):914-925. doi:10.1016/S1474-4422(15)00111-8.

73. Narbone MC, Musolino R, Granata F, Mazzù I, Abbate M, Ferlazzo E. PRES: posterior or potentially reversible encephalopathy syndrome? Neurol Sci Off J Ital Neurol Soc Ital Soc Clin Neurophysiol. 2006;27(3):187-189. doi:10.1007/s10072-006-0667-y.

74. Sweany JM, Bartynski WS, Boardman JF. "Recurrent" posterior reversible encephalopathy syndrome: report of 3 cases--PRES can strike twice! J Comput Assist Tomogr. 2007;31(1):148-156. doi:10.1097/01.rct.0000233127.21303.b9.

75. Roth C, Ferbert A. Posterior reversible encephalopathy syndrome: long-term follow-up. J Neurol Neurosurg Psychiatry. 2010;81(7):773-777. doi:10.1136/jnnp.2009.189647.

76. Legriel S, Schraub O, Azoulay E, et al. Determinants of Recovery from Severe 
Posterior Reversible Encephalopathy Syndrome. PLoS ONE. 2012;7(9):e44534. doi:10.1371/journal.pone.0044534.

77. Alhilali LM, Reynolds AR, Fakhran S. A multi-disciplinary model of risk factors for fatal outcome in posterior reversible encephalopathy syndrome. J Neurol Sci. September 2014. doi:10.1016/j.jns.2014.09.019.

78. Moon S-N, Jeon SJ, Choi SS, et al. Can clinical and MRI findings predict the prognosis of variant and classical type of posterior reversible encephalopathy syndrome (PRES)? Acta Radiol Stockh Swed 1987. 2013;54(10):1182-1190. doi:10.1177/0284185113491252.

79. Aranas RM, Prabhakaran S, Lee VH. Posterior reversible encephalopathy syndrome associated with hemorrhage. Neurocrit Care. 2009;10(3):306-312. doi:10.1007/s12028-009-9200-5. 


\section{FIGURE CAPTIONS}

Figure 1. 7-year-old girl treated with ciclosporin for allogeneic bone marrow transplantation (Patient 1).

Altered mental status and seizures. Brain CT scan (A) revealed a bilateral parietaloccipital edema and a frontal subarachnoid hemorrhage (black arrow). FLAIR images (B-F) showed cortical and subcortical edema in temporal, parietal and occipital lobes with additional involvement along the superior frontal sulcus and the watershed zones of the frontal lobes and in temporal regions. T2* gradient-recalled echo imaging $(G, H)$ detected microhemorrhage (white arrow) and subarachnoid hemorrhage (black arrow).

Figure 2. Initial and follow-up imaging in the same patient (Patient1) at day 90.

A. Subcortical white matter edema in temporo-occipital regions (white arrowhead) hyperintense on FLAIR and diffusion images with decreased ADC: reversibility of diffusion anomalies with complete recovery of the lesions at D90.

B. Cortical and subcortical edema in right parietal region (white arrow). Cortical hyperintensities lesions on FLAIR, diffusion-weighted images and decreased ADC: irreversible cortical lesions on FLAIR images at D90.

Figure 3. 69 year-old man with cerebellar syndrome and diplopia (Patient 2). Recurrent headaches for 4 days before hospitalization giving rise to suspicion of unstable hypertension. Symmetrical supra and infratentorial edema involving subcortical and deep white matter $(F)$ : corpus callosum $(A)$, posterior limb of internal capsule (B), brainstem $(C, D, E)$, middle cerebellar peduncles $(D)$ and cerebellum $(E, G)$.

Figure 4. Schematic representation of the various distributions of PRES lesions. Representation based on Bartynski et al. ${ }^{1}$, McKinney et al. ${ }^{22}$, Fugate et al. ${ }^{23}$ studies (a total of 332 cases of PRES).

Figure 5. Asymmetrical presentation in a 66 year-old female with metastatic breast cancer treated by chemotherapy (Patient 3).

Progressive restlessness and confusion without anomalies of the cerebrospinal fluid. Initial (A-F) and follow-up imaging at D30 (G) and D90 (H).

Left parieto-occipital extensive edema with mass effect and contralateral subcortical superior frontal sulcus edema on T2 (A) and FLAIR (B) images. Pure vasogenic edema on diffusion-weighted images (C) and ADC map (D). Hypoperfusion within the parietal occipital edema on post-contrast relative Cerebral Blood Volume (rCBV) map (E) with low rCBV $(\mathrm{rCBV}=0,4)$. No contrast-enhancement on T1-weighted post-contrast image (F). Complete but delayed radiological recovery at D90 (H).

Figure 6. Schematic representation of the three primary variations of traditional PRES imaging pattern.

6A. Superior Frontal Sulcus Pattern with frontal linear involvement located along the superior frontal sulcus.

6B. Holohemispheric Watershed Pattern spanning the frontal, parietal, and occipital lobes with vasogenic edema present at the watershed. 
6C. Dominant Parieto-Occipital Pattern with involvement of the parietal and occipital white matter and cortex with variable involvement of the temporal lobes.

Figure 7. Basal ganglia and cortico-meningeal involvement in a thirty-four-year-old female with malignant hypertension and headaches 4 days after delivery (Patient 4). FLAIR sequences (A, D), T1-weighted image (E), post-contrast FLAIR (B) and T1weighted images $(\mathrm{C}, \mathrm{F})$.

Cortical and subarachnoid hyperintensities on FLAIR (A) with leptomeningeal enhancement more remarkable on FLAIR post-gadolinium sequence (B) than on T1 post injection sequence $(C)$. Bilateral symmetric hyperintensity of the striatum and focal hyperintensity in the splenium of corpus callosum on FLAIR (D) with striatal enhancement on T1-weighted post-contrast $(F)$ images.

Figure 8. 21-year-old female with systemic lupus erythematosus (Patient 5).

Acute malignant hypertension, headaches and status epilepticus following treatment withdrawal. Favourable clinical evolution under anti-epileptic and anti-hypertensive drugs. Initial and follow-up imaging at D0, D10 and D40.

D0: bilateral corticosubcortical FLAIR hyperintensities in the occipital lobes and anterior watershed regions with increased Cerebral Blood Flow (CBF) on CBF map generated by Arterial Spin Labeling perfusion (ASL). Follow-up MRI at D10 and D40: regression of the edema and progressive normalization of the CBF.

Figure 9. Same patient (Patient 5) with PRES recurrence 6 months later.

Initial MRI (D0): increased perfusion in occipital regions and anterior watershed regions on CBF color map $(F)$ with slight focal cerebellar and occipital hyperintensities on FLAIR $(A-C)$, without cortical signal abnormality on DWI (D-E).

Figure 10. Patient 5, three days after figure 9 images (D3), neurological impairment and seizure.

Extensive cerebellar vasogenic edema (A) complicated with hydrocephalus. Involvement of the parieto-occipital and frontal white matter (B-C) with increased diffusion (D) and $A D C(E)$, increased perfusion in occipital regions and anterior watershed regions on CBF color map (F).

Figure 11. Patient 5 at D3: T2 washout on diffusion images and cortico-meningeal involvement

Cerebellar white matter edema (black arrowhead) on T2 (A), b0 (B), b1000 (C) diffusionweighted images (DWI) and ADC map (D): hypointense lesions on b1000 DWI with high ADC values.

Subarachnoid hemorrhage (black arrow) in cerebellar sulci (E) on T2 Star Weighted ANgiography (SWAN). Leptomeningeal (white long arrow), intraparenchymal (white arrowhead) and cortical (white short arrow) enhancement on post-contrast T1-weighted images $(\mathrm{F}-\mathrm{H})$.

Figure 12. Decreased perfusion in a 55-year-old female with history of psoriatic arthritis treated with Methotrexate, severe renal impairment and hypertension (Patient 6) 
presenting with acute malignant hypertension, confusion, disorientation and right lateral homonymous hemianopsia.

Vasogenic edema involving the parietal occipital white matter and the superior frontal sulcus on FLAIR sequences (A-D) with increased ADC (E) and decreased perfusion within parietal occipital edema on rCBV map from contrast-enhanced perfusion and FLAIR fusion imaging $(F, G)$.

Figure 13. Hemorrhages and vascular abnormalities in a 38-year-old female with altered mental status (Patient 7).

Left frontal hematoma (white arrow) with intraventricular (black arrow) and subarachnoid hemorrhage on FLAIR (A-C) and T2* (D-E) images. Cerebellar and corticosubcortical parieto-occipital edema (A-C). Multifocal cerebral vasoconstriction in anterior and middle cerebral arteries branches with string-of-bead appearance on 3D TOF MR angiography (F) and catheter angiography (G, H) (arrowheads). 


\section{ACCEPTED MANUSCRIPT}

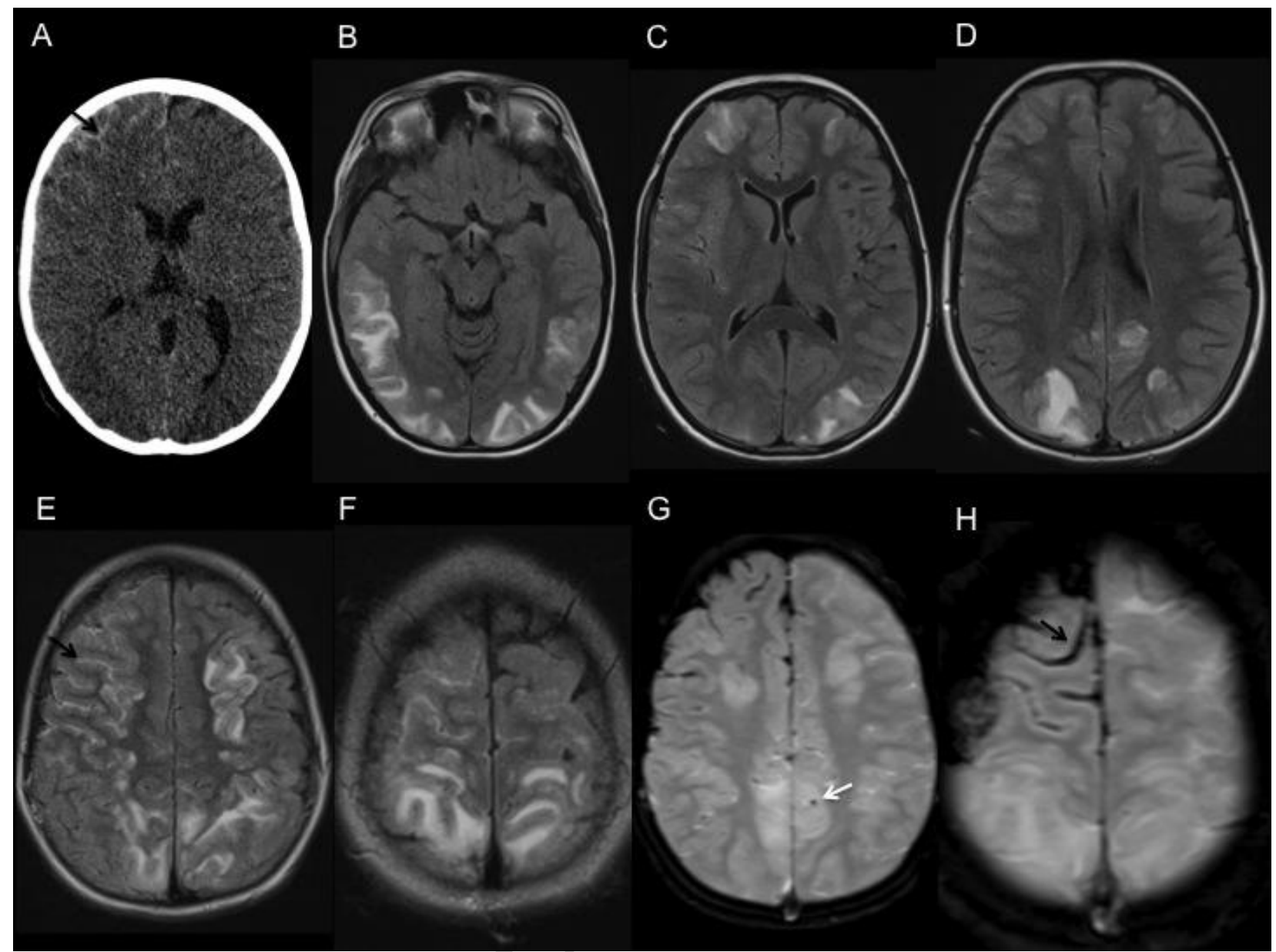

Figure 1

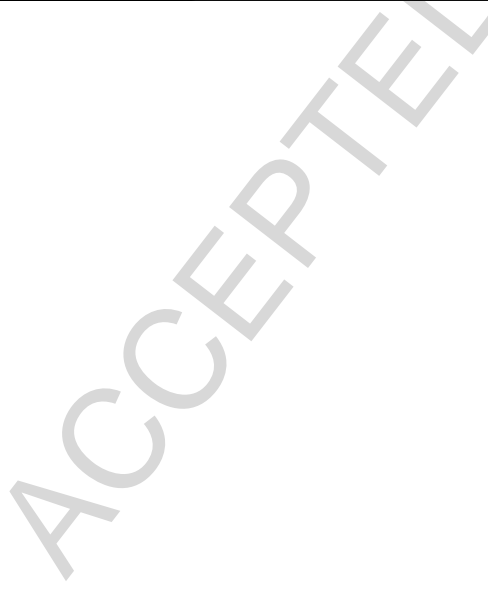




\section{ACCEPTED MANUSCRIPT}

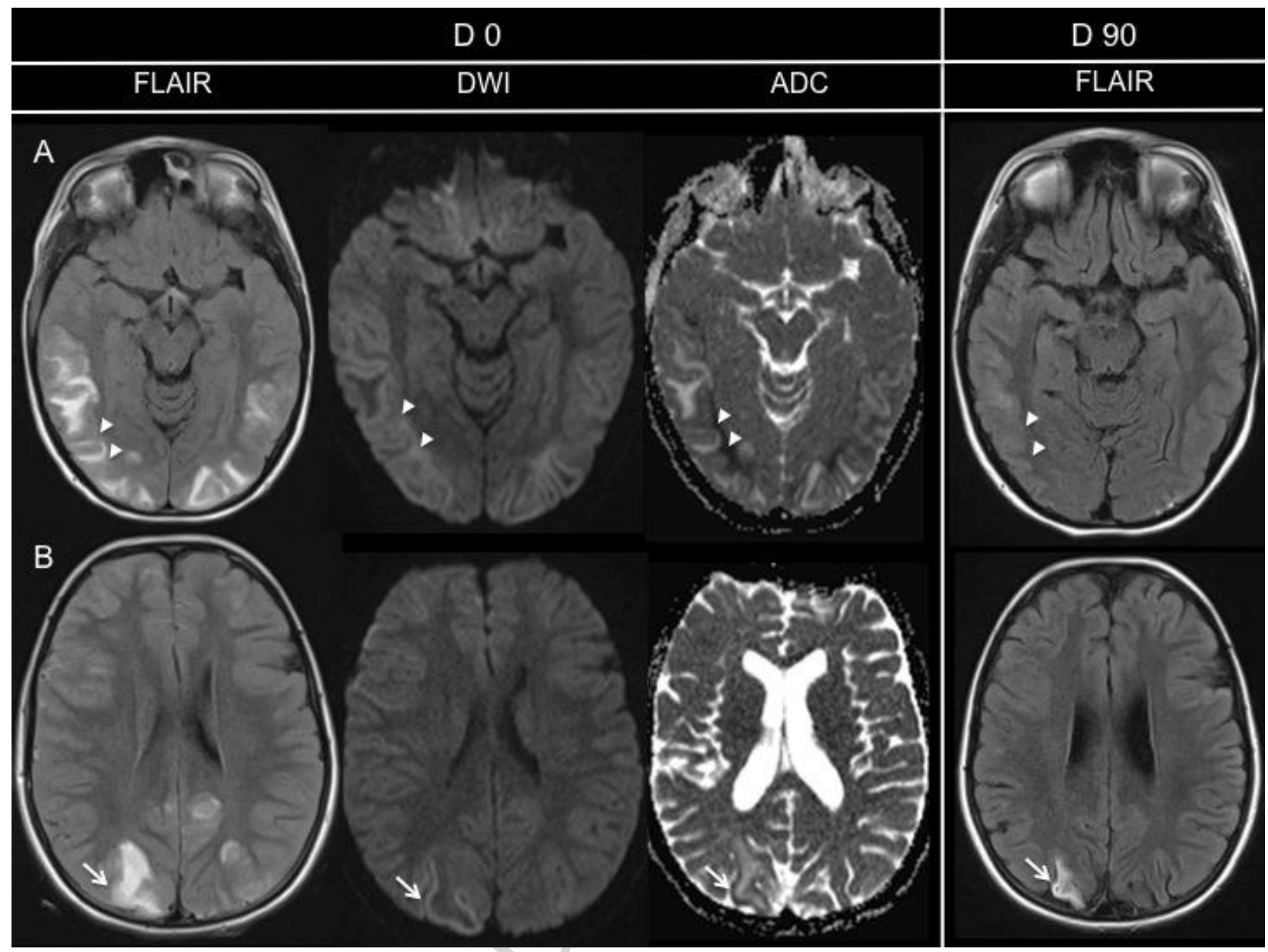

Figure 2 


\section{ACCEPTED MANUSCRIPT}

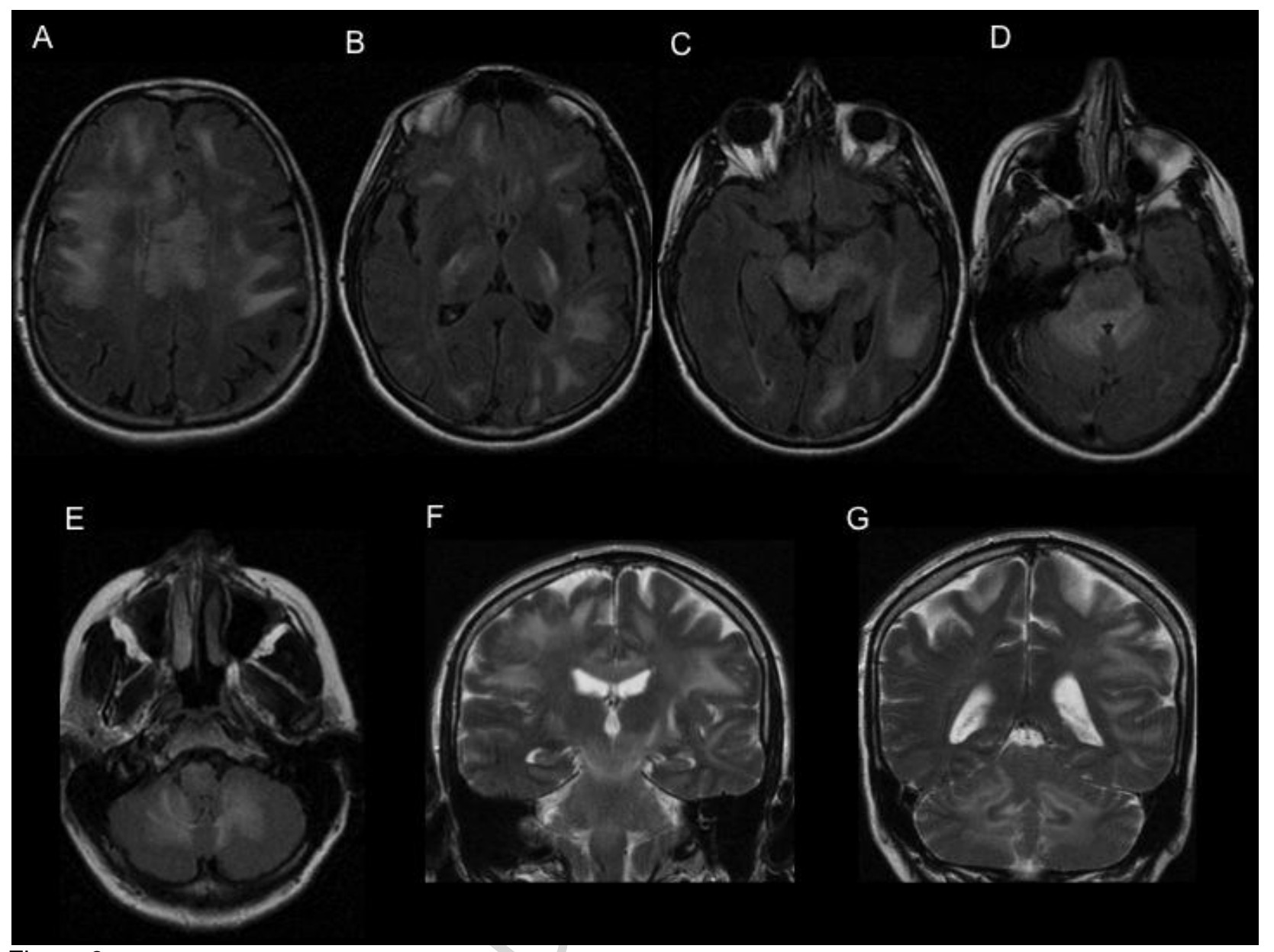

Figure 3 
$<30 \% \quad \geq 30 \% \quad \geq 50 \% \quad \geq 60 \% \quad \geq 70 \% \quad \geq 90 \%$
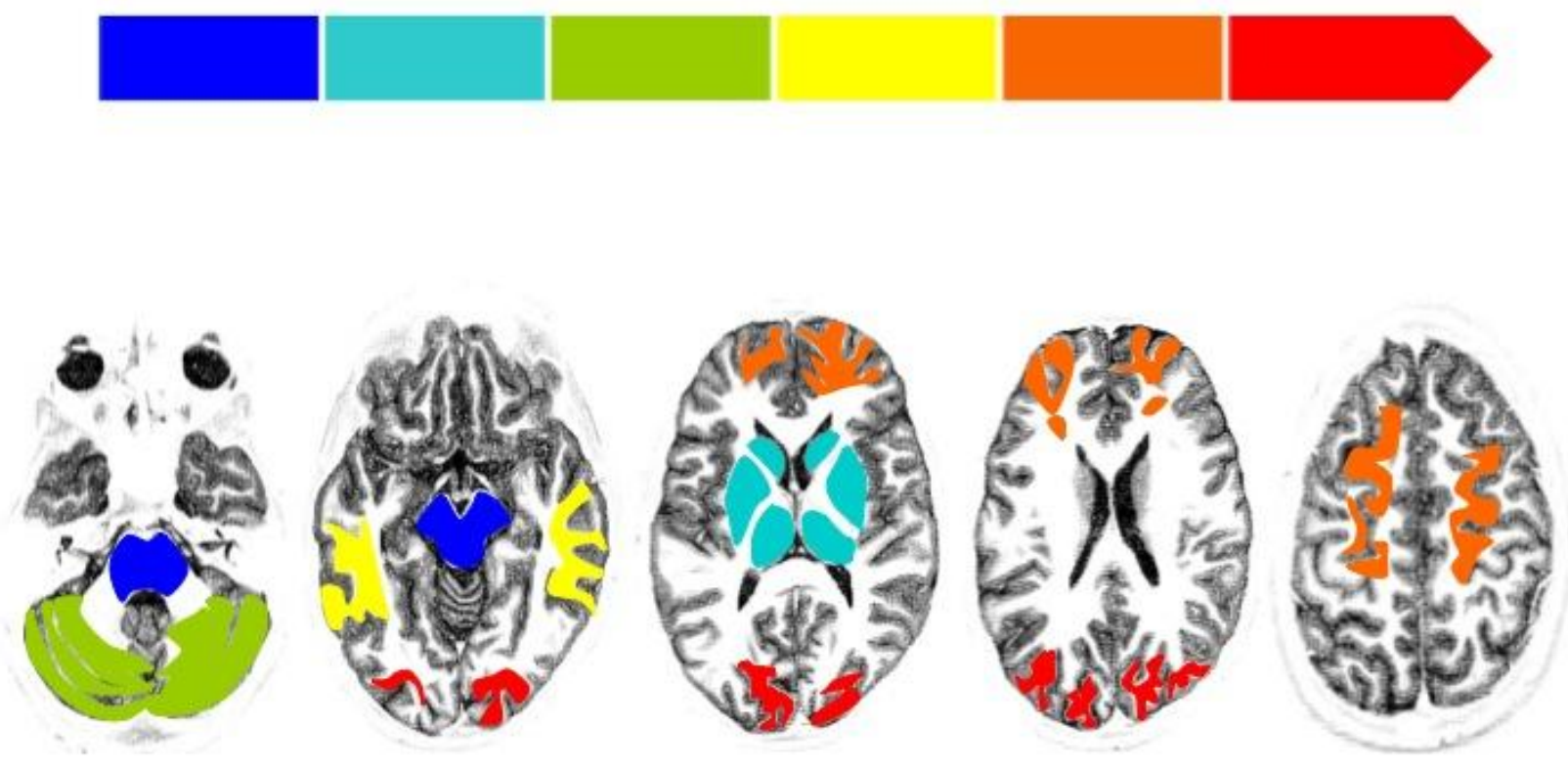

Figure 4 


\section{ACCEPTED MANUSCRIPT}

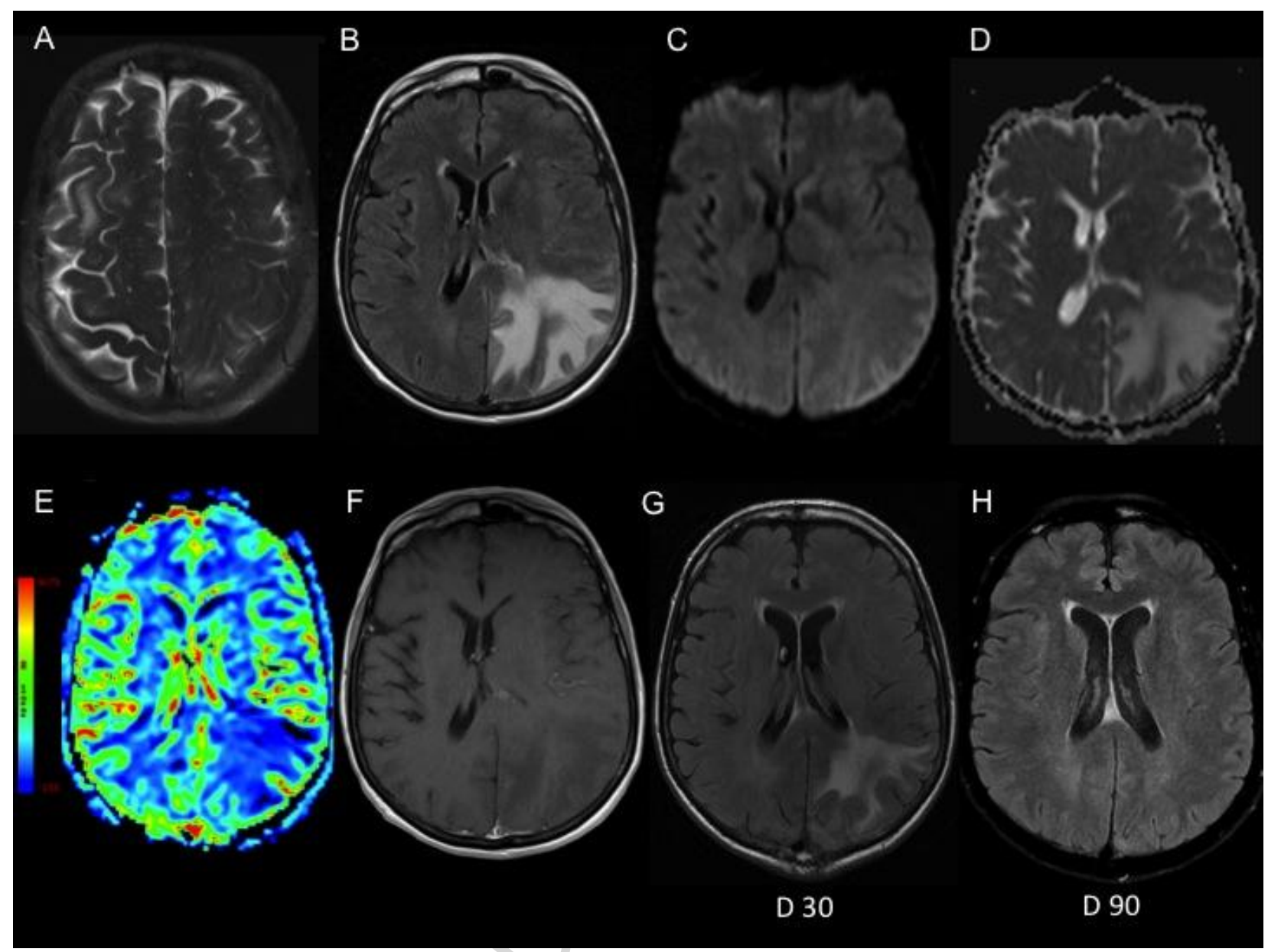

Figure 5 


\section{ACCEPTED MANUSCRIPT}
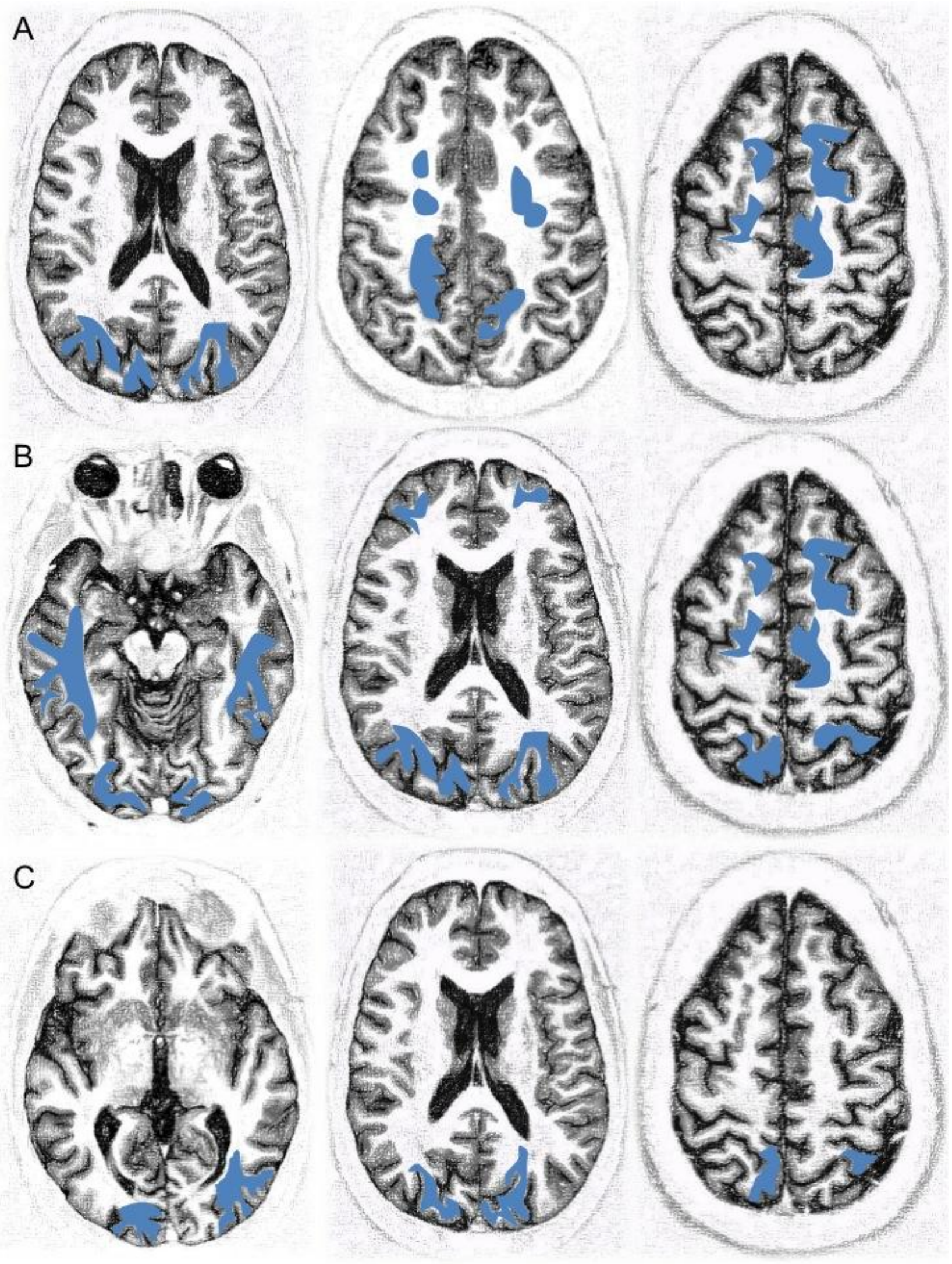

Figure 6 


\section{ACCEPTED MANUSCRIPT}

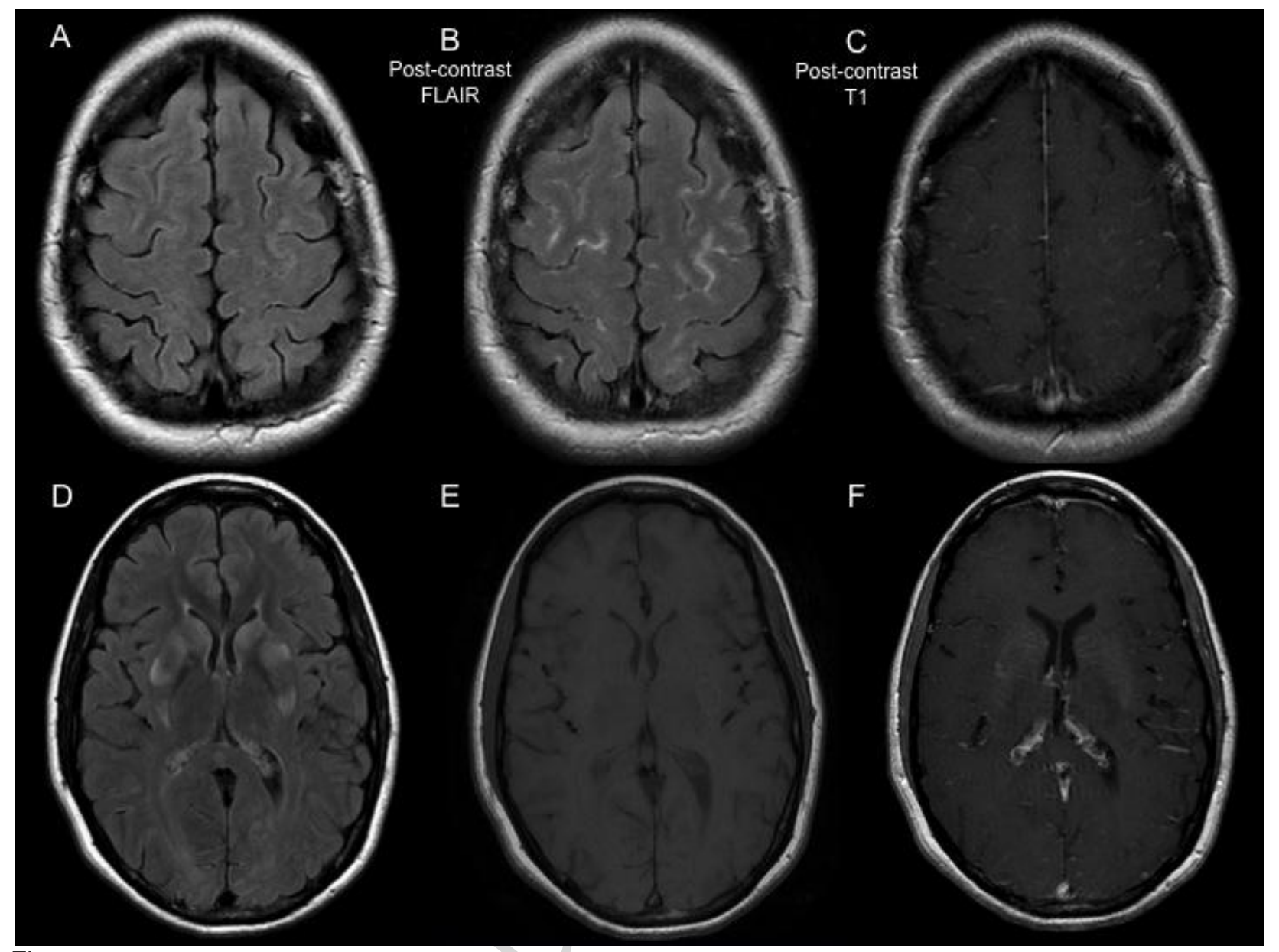

Figure 7 


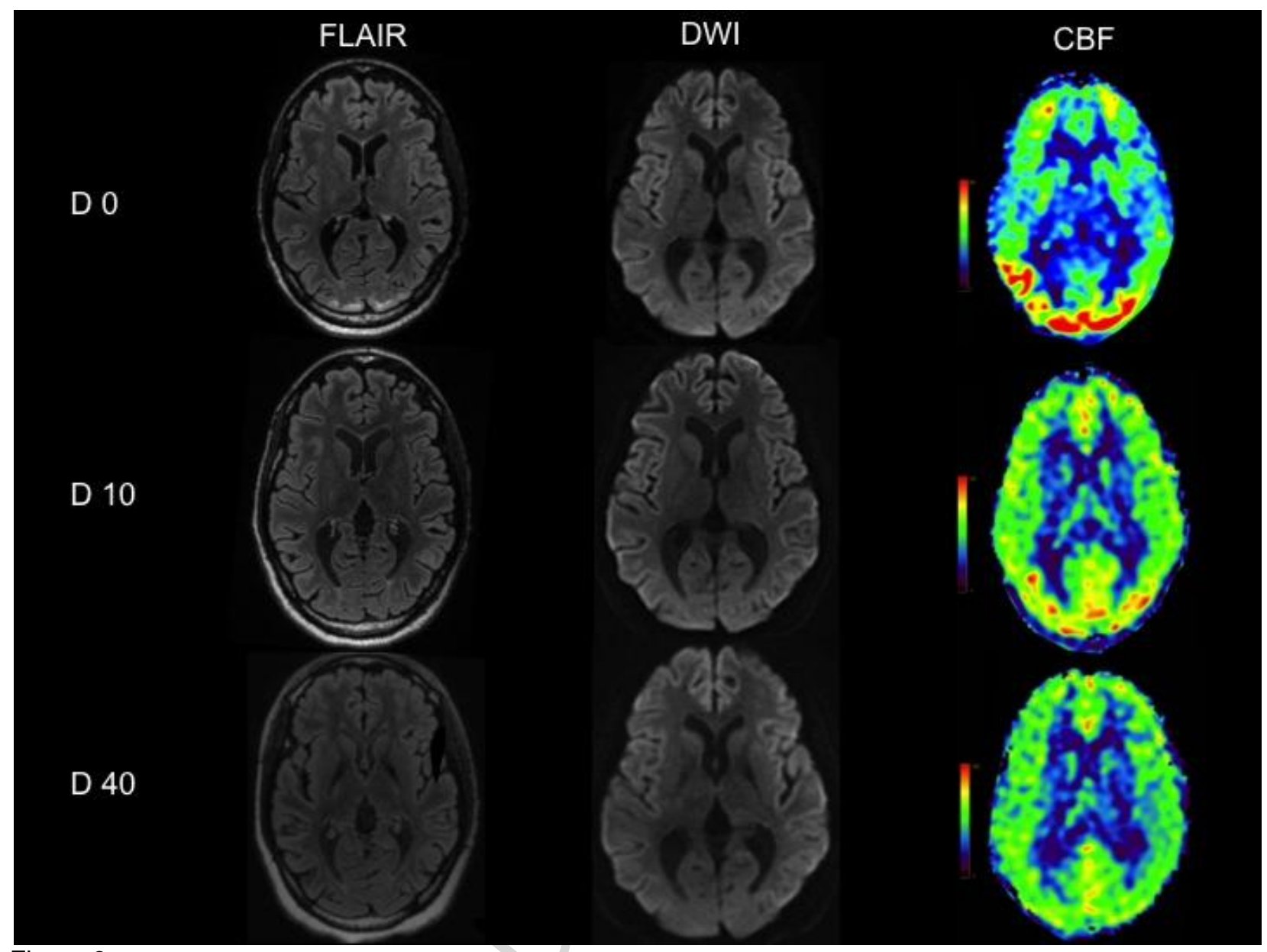

Figure 8 


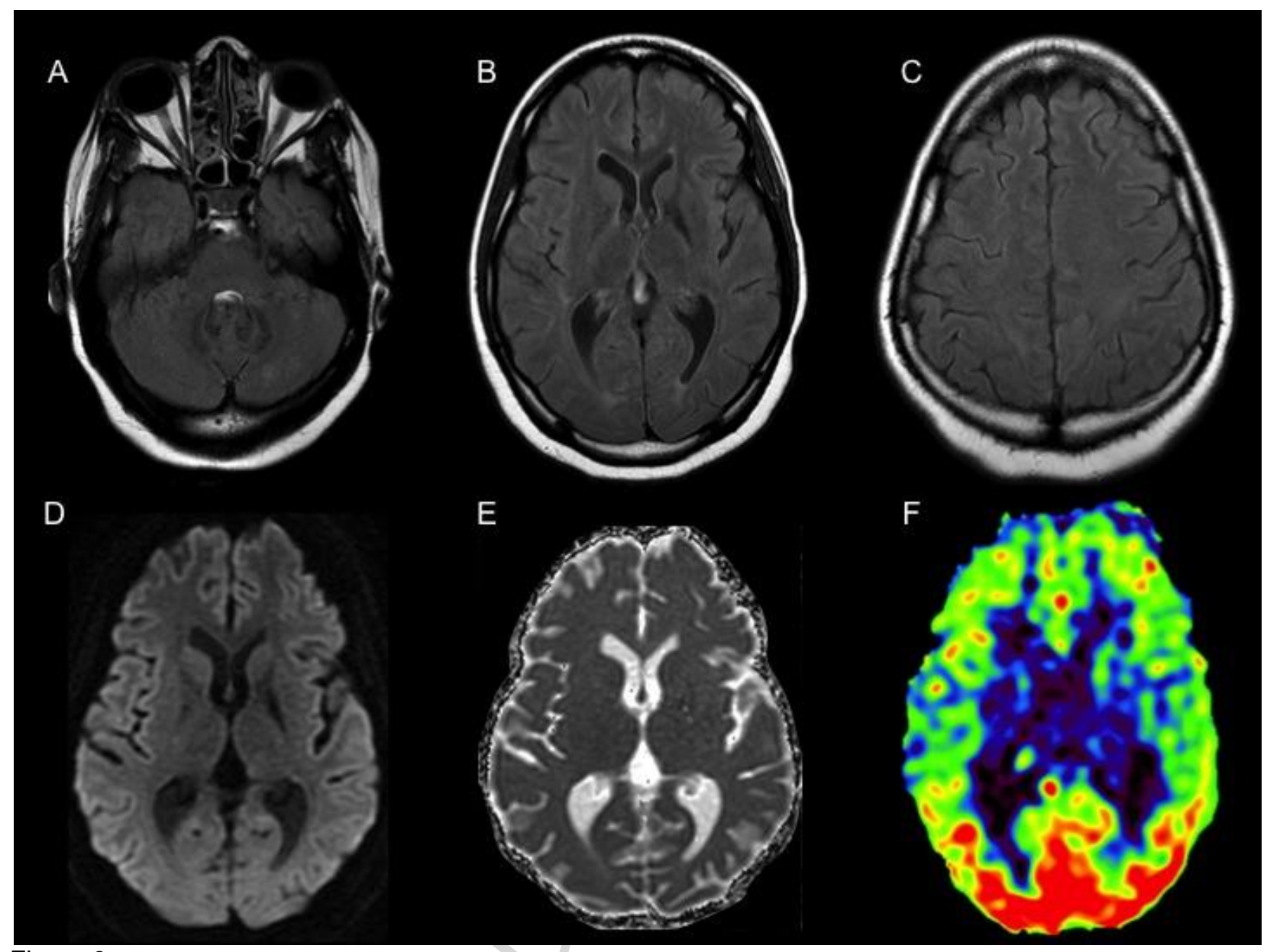

Figure 9 


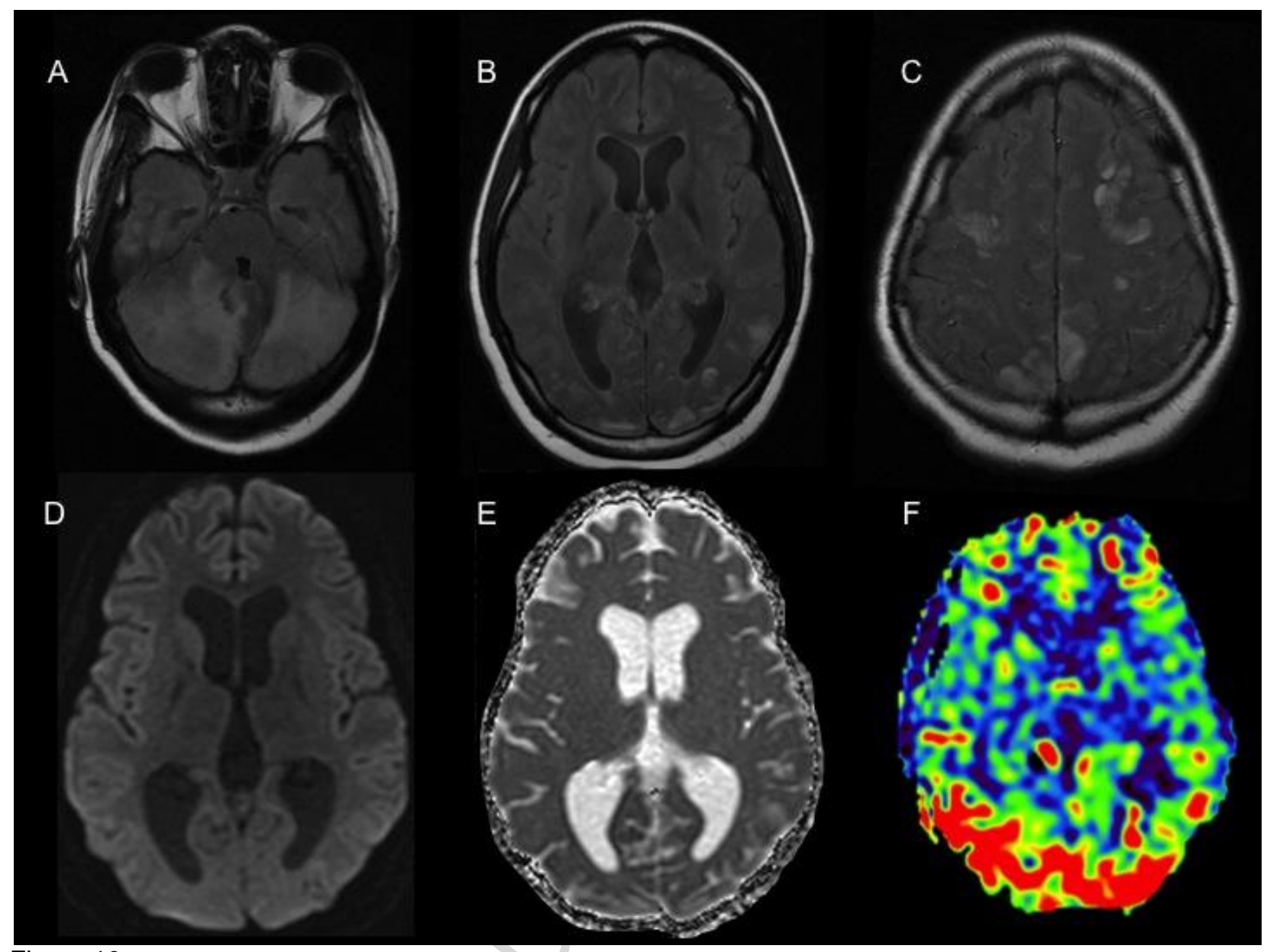

Figure 10 


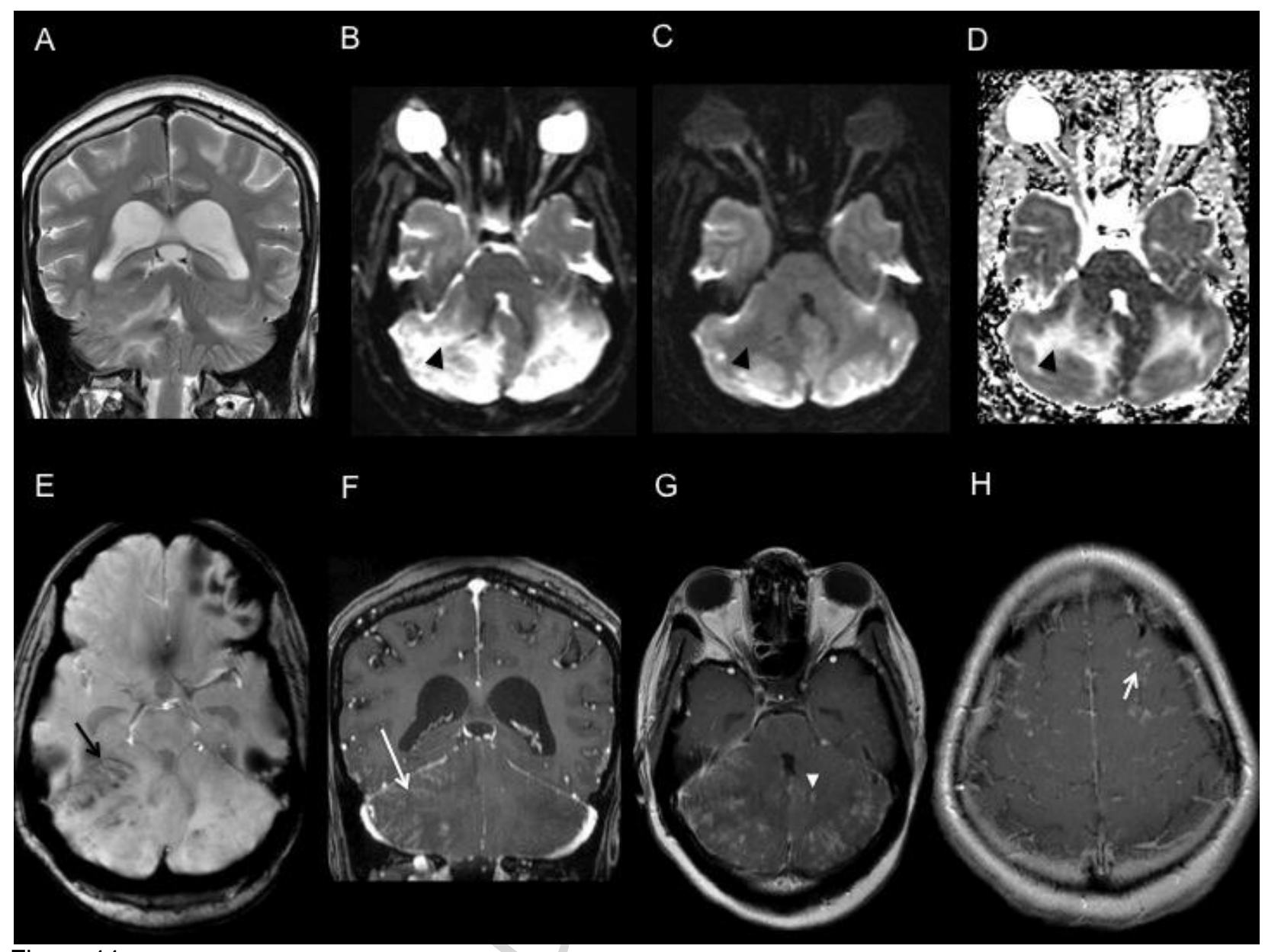

Figure 11 


\section{ACCEPTED MANUSCRIPT}

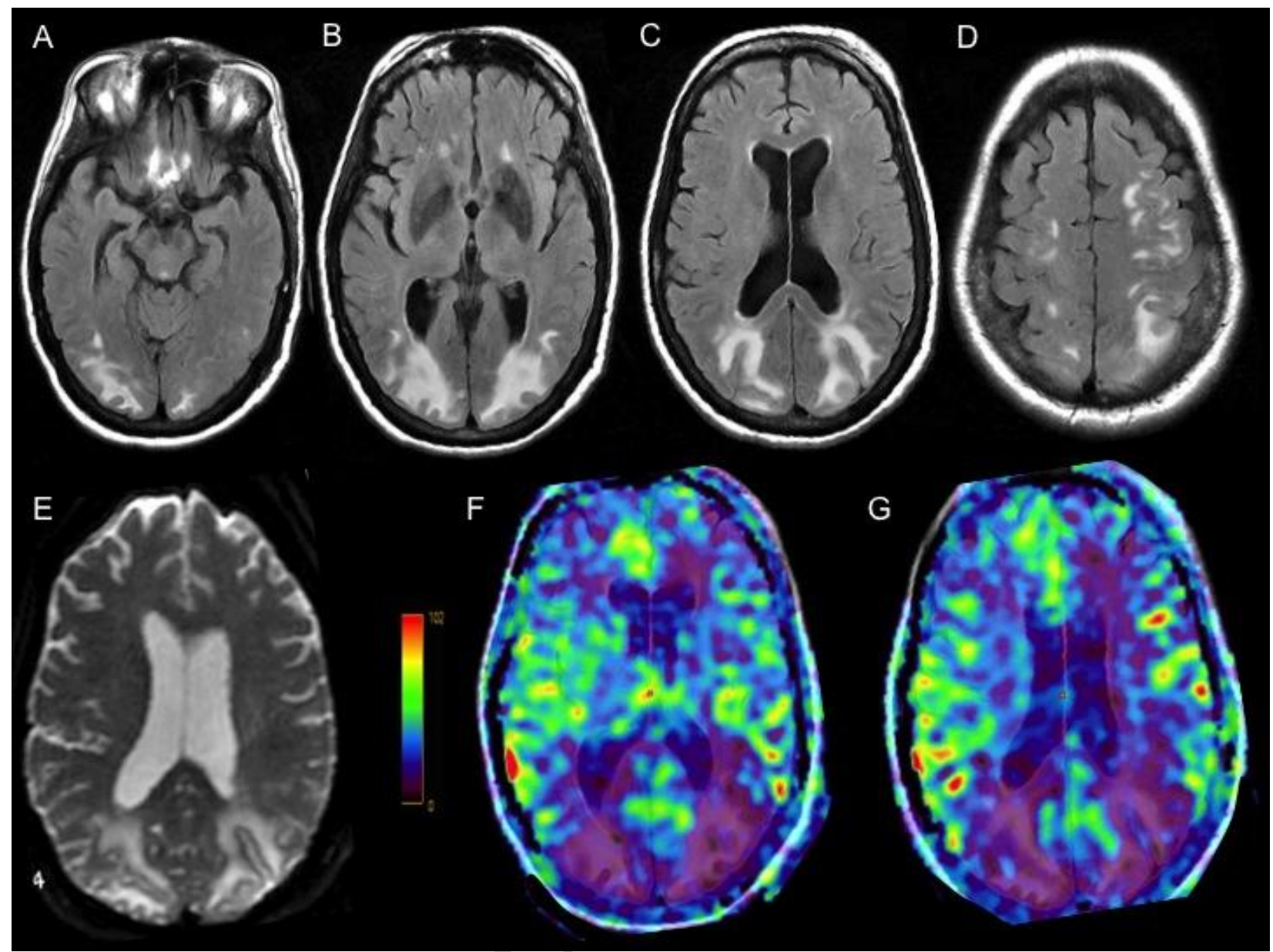

Figure 12 


\section{ACCEPTED MANUSCRIPT}

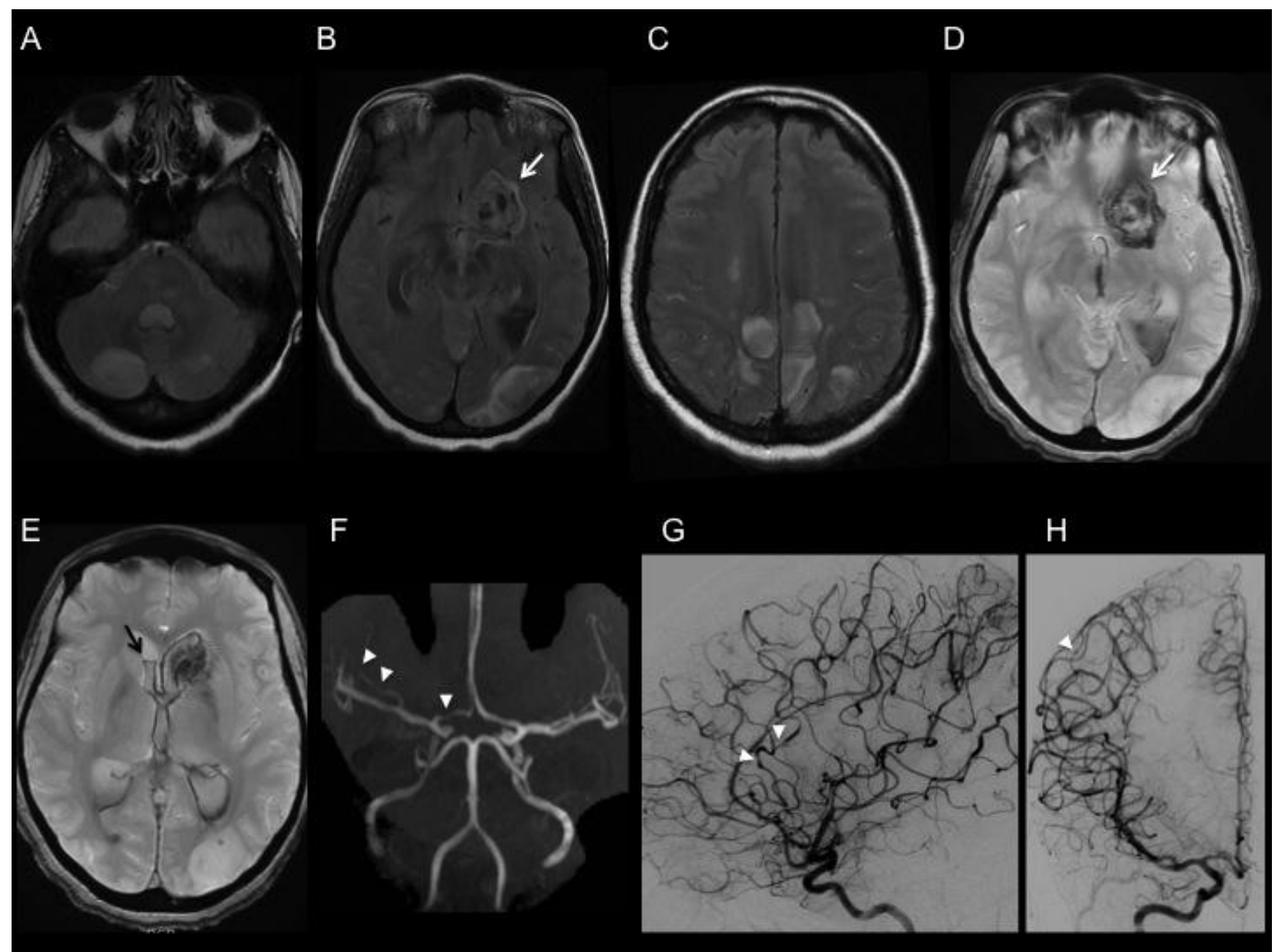

Figure 13 


\section{Highlights}

- MRI is an efficient tool for early diagnosis and follow-up in PRES

- hemorrhage is a common complication

- decrease in ADC values does not always correlate with nonreversibility of the lesions

- perfusion MR imaging can demonstrate increased or decreased perfusion

- multifocal cerebral vasoconstriction is commonly observed 